
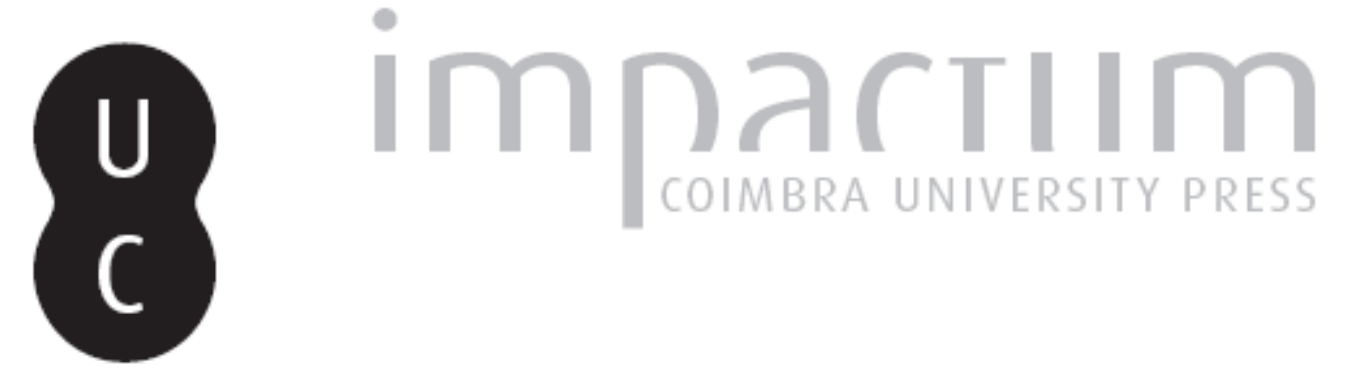

Traços de Eros e Mania: as Cartas de Mariana Alcoforado e as Heroides de Ovídio Autor(es): $\quad$ Carvalho, Ana Seiça

Publicado por: Associação Portuguesa de Estudos Clássicos; Instituto de Estudos Clássicos

URL persistente:

URI:http://hdl.handle.net/10316.2/30448

DOI: DOI:http://dx.doi.org/10.14195/0872-2110_51_13

Accessed : $\quad$ 26-Apr-2023 08:50:17

A navegação consulta e descarregamento dos títulos inseridos nas Bibliotecas Digitais UC Digitalis, UC Pombalina e UC Impactum, pressupõem a aceitação plena e sem reservas dos Termos e Condições de Uso destas Bibliotecas Digitais, disponíveis em https://digitalis.uc.pt/pt-pt/termos.

Conforme exposto nos referidos Termos e Condições de Uso, o descarregamento de títulos de acesso restrito requer uma licença válida de autorização devendo o utilizador aceder ao(s) documento(s) a partir de um endereço de IP da instituição detentora da supramencionada licença.

Ao utilizador é apenas permitido o descarregamento para uso pessoal, pelo que o emprego do(s) título(s) descarregado(s) para outro fim, designadamente comercial, carece de autorização do respetivo autor ou editor da obra.

Na medida em que todas as obras da UC Digitalis se encontram protegidas pelo Código do Direito de Autor e Direitos Conexos e demais legislação aplicável, toda a cópia, parcial ou total, deste documento, nos casos em que é legalmente admitida, deverá conter ou fazer-se acompanhar por este aviso.

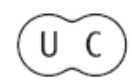




\section{Boletim de}

\section{Estudos Clássicos}

Associação Portuguesa de Estudos Clássicos Instituto de Estudos Clássicos

Coimbra

Junho de 2009 


\title{
Traços de ERos e Mania: As Cartas de MARIANA AlCOFORAdo E AS HEROIDES DE OVÍDIO*
}

\begin{abstract}
"Vous m'avez consommée par vos assiduitez, vous m'avez enflamée par vos transports, vous m'avez charmée par vos complaisances, vous m'avez asseurée par vos sermens, mon inclination violente m'a seduite, et les suites de ces commencemens si agréables et si heureux, ne sont que des larmes, que des soûpirs, et qu'une mort funeste, sans que je puisse y porter aucun remede"

Mariana, Lettres Portugaises, Quarta Carta, p. $85^{1}$
\end{abstract}

\section{As Lettres Portugaises de Mariana Alcoforado}

O grande investigador, historiador e verdadeiro estudioso da "questão das cartas", Luciano Cordeiro, descobriu uma Mariana Alcoforado no Convento da Conceição, em Beja, o mais consagrado convento da região alentejana. Sabe-se, apenas, que nasceu a 22 de Abril de 1640, que era de origem fidalga, da família dos Alcoforado, e que entrara para o convento com 11 anos. Nos documentos encontrados, assinalava-se a data em que a freira tinha professado, com 16 anos, em 1656, e a data do seu falecimento, em 1723, aos 85 anos. Quanto ao cavaleiro francês, destinatário das cartas amorosas, Noël Bouton, de nobre historial familiar, com origem em Borgonha, entrou ao serviço dos Portugueses em 1663. Acerca de Bouton, conde de Saint-Léger e, mais tarde, conde e marquês de Chamilly, dizia-se que era uma bela figura de homem, embora um pouco espalhafatoso, de temperamento bastante estúpido e de parca cultura.

A primeira edição destas cartas de amor é de Claude Barbin e data de 4 de Janeiro de 1669; logo de seguida, foi publicada uma edição de Pierre de Marteau e, ainda nesse ano, Barbin publicou de novo as cinco cartas originais e mais sete. Mais cartas vão sendo forjadas e as edições multiplicam-se a tal

* Adaptação de um trabalho realizado sob a orientação do Professor Carlos Ascenso André, no âmbito do seminário Matrizes Latinas da Poesia Ocidental, inserido no Mestrado em Poética e Hermenêutica.

1 Seguimos de perto a primeira edição, de Claude Barbin, com tradução de Eugénio de Andrade (Cartas Portuguesas). 
ponto que em 1923 existiam já cento e trinta edições diferentes espalhadas pela Europa e traduzidas em diversas línguas.

Numerosos foram os estudiosos a quem interessou esmiuçar a questão da autoria das Cartas e que procuraram perceber até que ponto uma freira portuguesa as poderia ter escrito. No entanto, a dúvida e a polémica mantêmse: foram escritas originalmente em francês ou são uma tradução francesa de um original português? ${ }^{2}$ Poderia até tratar-se de um original francês, escrito por uma freira francesa... Chegou a afirmar-se que teria sido o próprio Chamilly o seu autor ou até mesmo Guilleragues, um editor, a escrevê-las. Eugénio de Andrade lança uma proposta diferente, acreditando na possibilidade de ter sido uma mulher de salão a redigir tais cartas ${ }^{3}$. Sabemos que era recorrente circularem cartas de foro íntimo entre os cortesãos, nos salões, pois era moda o género epistolar. O próprio tom das súplicas, o jogo de angústia, a forma de retratar a dor, "os inegáveis cuidados literários" (nas palavras de A. Gonçalves Rodrigues ${ }^{4}$ ) e a ideia da fragilidade feminina,

2 Cf. A. B Fonseca, Mariana Alcoforado, a freira de Beja e as "Lettres Portugaises”, pp. 61-98. Luciano Cordeiro, no seu aprofundado estudo sobre a freira portuguesa, afirma-nos que, para muitos, o livro publicado por Barbin era já uma tradução francesa do original (Teófilo Braga, por exemplo, criticava o francês das cartas apresentadas por Barbin, por se denotar a sintaxe portuguesa). Alexandre Herculano, pelo contrário, e ainda Camilo Castelo Branco, Afonso Lopes Vieira e A.Gonçalves, afirmavam tratar-se de um original francês, pois era uma língua muito falada em Portugal e uma freira poderia, em princípio (e para mais descendente de família abastada e nobre), possuir essa formação intelectual. Também sobre as Heroides de Ovídio se derrama alguma controvérsia, a questão da autenticidade de certas cartas do corpus, já que, nos Amores (2, 18, 21 e sqq), Ovídio faz referência a algumas cartas, insinuando que seria Sabinus, seu amigo, o verdadeiro autor. Alguns críticos reduziam a dez as verdadeiras Heroides, sendo as mais suspeitas a 9, a 15 e as duplas, 16-21 (com resposta dos respectivos amantes), sobretudo pela sua métrica diferente.

${ }^{3}$ Eugénio de Andrade, um dos muitos autores portugueses que traduziu, mais recentemente, as Cartas Portuguesas de Mariana Alcoforado defende que "Quem falava nas Cartas estava mais próximo de qualquer dama cuja educação tivesse sido confiada aos cuidados da marquesa de Sevigné que de uma moça encerrada em quatro paredes, sem outro horizonte que não fosse o seu amor... e o céu cru do Alentejo", Cartas Portuguesas, p. 7.

${ }^{4}$ A. Gonçalves Rodrigues, Sobre a autoria das 'Lettres Portugaises', p. 32. 
sofrendo por amor, tudo nas cartas nos revela lugares-comuns da literatura parisiense, bastante deslocada da possível pena de uma franciscana de Beja.

E naquela época, seria assim tão fácil namorar uma freira nas grades do locutório? Seria assim tão simples entrar à socapa num convento? Confiemos apenas nos ímpetos do amor, sabendo de antemão que quaisquer que fossem as dificuldades, os amantes arranjariam decerto forma de as derrubar. Além de que, tal como Ovídio aconselhava, os perigos davam maior ênfase ao desejo e ao sentimento amoroso ${ }^{5}$. A verdade é que Mariana se refere aos encontros amorosos nos seus aposentos

\section{Convent,}

j'estois troublée par le peril que vous couriez en entrant dans le Quinta Carta, p. 98

Quoy! Tous mes désirs seront donc inutiles, et je ne vous verray jamais en ma chambre avec tout l'ardeur et tout l'emportement, que vous me faisiez voir?,

Segunda Carta, p. 71

je sors le moins qu'il m'est possible de ma chambre, où vous estes venu tant de fois,

Segunda Carta, p. 74.

Muita tinta correu já acerca das misteriosas cartas portuguesas ${ }^{6}$. Vamos tomá-las, pois, muito simplesmente, como o resultado de um amor desesperado de uma freira. Chamemos-lhe Mariana, seguindo a tradição, e deixemos propositadamente de lado a controvérsia que a envolve. Interessanos estudar os sentimentos descritos por este "eu" feminino, que lamenta o seu amor alienado e a sua entrega a um amante que tão facilmente a abandonou.

Propomos traçar aqui um paralelo literário entre as cinco cartas oficiais do corpus alcoforadista e algumas das cartas imaginadas e saídas do estilete de Ovídio, tendo naturalmente em conta a grande diferença que as distingue e os dezoito séculos que as separam: enquanto que acerca de Mariana nada sabemos com certeza, julgando-a, por isso, a autora original e um "eu"

${ }^{5}$ Cf. Ovídio, Ars Amatoria, 3.579-586.

${ }^{6}$ Para um estudo mais detalhado, cf. A. B. Fonseca, op. cit., capítulo V, pp. 127-153 e L. Cordeiro, Soror Mariana, a freira portuguesa e a obra de A. Gonçalves Rodrigues. 
feminino por excelência, Ovídio é, sem dúvida, um autor textual masculino que constrói um "eu” feminino que por sua vez redige as epístolas.

\section{O topos da mulher abandonada}

Autor de obras como Arte de Amar e Amores, compêndios de aconselhamento para o adultério, Ovídio dedicou-se ainda à mitologia, uma das suas paixões, como prova nas Heroides, mas com maior ênfase nas Metamorfoses, e legou-nos ainda, no final da sua vida, um belíssimo lamento, os Tristia e as Epistulae Ex-Ponto, uma das fontes primordiais dos mais conhecidos topoi de toda a literatura de exílio.

As Heroides apresentam, de alguma forma, uma estrutura precursora na literatura epistolar: abordando o tema da mulher sofredora que lamenta ter sido abandonada, o autor apresenta-nos figuras conhecidas da história e da mitologia ${ }^{7}$. Apesar da sua originalidade, a obra é considerada por alguns estudiosos bastante monótona e repetitiva. Outros, pelo contrário, defendem a imensa variedade das Cartas, o estilo contrastivo de cada uma, a progressão psicológica das personagens 8 ... Apreciamos o seu estilo espantosamente "barroco", no que diz respeito aos recursos estilísticos carregados e à profusão de ironias e de grandes floreados exagerados: os desmaios, os ardores amorosos, as lágrimas que sufocam, a dor que consome o peito devido à separação dos amantes e que os leva a cometer loucuras.

A todas as mulheres retratadas subjaz uma situação semelhante: abandonadas que foram pelos amantes, aguardam em vão a promessa do seu retorno e lamentam as recordações dilacerantes que as enlouquecem. Mariana, freira enclausurada, procurara subjugar os seus sentimentos ao recato e à regra do seu hábito franciscano, mas o amor sentido e o despeito do abandono injustificado tornam-se demasiado dolorosos: tu m'as trahie par des espérances trompeuses, Primeira Carta, p. 64. Assim também Dido, rainha de Cartago, tentara refrear a sua paixão pelo estrangeiro que a visitava,

7 Há quem defenda que por trás destas mulheres despeitadas estão veladas as amantes mais conhecidas e as coquettes do tempo do Imperador Augusto (M. Prévost, Hérö̈des, XIII).

8 Apesar de algumas críticas que os estudiosos apontam às Heroides (veja-se L. P. Wilkinson, Ovid Surveyed 34-48, sobretudo p. 39), H. Jacobson defende a originalidade ovidiana e a sua tentativa de recriar e elevar os mitos a uma nova dimensão e perspectiva (Ovid's Heroides, p. 354).

${ }^{9}$ L. P. Wilkinson, op. cit., p. 39. 
submetendo o seu amor desenfreado à frieza de uma rainha para com o seu súbdito, mas em vão, pois numa noite de tempestade deram-se um ao outro $(H ., 7.93)^{10}$; e o mesmo Fedra, que procurava acalmar a febre ardente que sentia pelo enteado, evitando um possível incesto que, apesar de terrível, fortemente a tentava (H.4).

Nas suas cartas, Mariana desfaz-se numa fonte torrencial de súplicas e o seu lamento pela perda de tão grande amor é acompanhado de um profundo ardor

Pourquoy m'avez vous fait connoître l'imperfection et le désagréement d'un attachement qui ne doit pas durer eternellement?,

Quinta Carta, p. 96

a um tempo resignado e vingador. Desejava que o ex-amante não pertencesse a mais ninguém, se não tinha sido dela, então que não se unisse a outra mulher até ao fim dos seus dias (vide Terceira Carta, p. 79).

As perguntas e as censuras que Mariana lança ao seu pobre coração dilaceram-na. Começando pela primeira das cartas, sentimos a grande desilusão da vida da jovem freira: que um amor que ela julgava tão grandioso se tenha reduzido a cinzas:

Comment se peut-il faire que les souvenirs des momens si agréables, soient devenus si cruels? Et faut-il que contre leur nature, ils ne servent qu'à tyranniser mon coeur? Hélas! vostre dernière lettre le réduisit en un estrange état: il eut des mouvements si sensibles qu'il fit, ce semble, des efforts, pour se séparer de moy, et pour vous aller trouver,

Primeira Carta, p. 65.

Fílis da mesma maneira se martiriza

Dic mihi, quid feci, nisi non sapienter amaui?

Crimine te potui demeruisse meo.

Unum in me scelus est, quod te, scelerate, recepi,

Sed scelus hoc meriti pondus et instar habet

10 Virgílio terá imaginado a relação de Dido e Eneias com o propósito de reafirmar a firmeza do herói em cumprir os fados, submetendo o amor ao destino e não se deixando arrebatar pelas emoções (cf. C. A. André, Caminhos do Amor em Roma, p. 239). 
Iura, fides ubi nunc comissaque dextera dextrae,

Quique erat in falso plurimus ore deus?

Promissos socios ubi nunc Hymenaeus in annos,

Quid mihi coniugii sponsor et obses erat?

"Diz-me: que fiz eu, a não ser ter amado sem medida?

Por meu erro, fui capaz de merecer-te;

um só crime cometi, ó desgraçado, o de te ter acolhido,

mas esse crime tem o peso e a grandeza de um mérito.

Juramentos, fidelidade, onde estão agora? E a mão que na mão se

E o deus que em fingidas palavras se multiplicava?

[enlaçou?

Onde está, agora, a prometer anos de companheirismo, Himeneu que era, para mim, aval e garantia de enlace?" 11

H. 2.27-33;

E do mesmo modo, Briseida, princesa cativa a quem Aquiles matara o marido e a mãe, se vê de novo abandonada por aquele que a conquistara e não compreende como uma paixão acesa e fogosa se reduza a nada $(H$. 3.4142).

Mariana não compreende, ou não deseja compreender, o porquê da ausência do amante (ce procedé est bien plus d'un Tyran, attaché à persécuter, que d'un Amant, qui ne doit penser qu'à plaire?, Quarta Carta, p. 86) e roga-lhe, desde o primeiro momento em que lhe escreve, que não a trate com indiferença (vous ne devriez pas me mal-traiter, comme vous faites, par un oubly, qui me met au désespoir, Segunda Carta, p. 70). A sua indignação é um crescendo, por se aperceber de que as suas cartas ficam sem resposta (vide Terceira Carta, p. 75). Também Dido não concebe as razões e os fados que obrigam Eneias a partir. Ele poderia fundar Roma e voltar para os seus braços ou levá-la com ele...

As despedidas do seu amante, frias e provavelmente acompanhadas de falsas desculpas, levam Mariana a reflectir na veracidade do amor que lhe era prometido (vide Terceira Carta, p. 76). De igual modo, Dido vê Eneias preparar-se para partir sem nada lhe dizer, uma fuga demasiado cobarde, estranha à figura daquele que era considerado um herói. Fílis, pelo seu lado,

11 As traduções de fragmentos das Heroides são de Carlos Ascenso André, ainda inéditas, a quem agradeço a disponibilização do seu texto. 
devido à demora de Demofoonte, que lhe pedira que por ele esperasse, principia a duvidar dos sentimentos do jovem (H. 2.94-101). Ao contar as fases da Lua, apercebe-se de que já muitas vezes se cumprira o seu ciclo, e que há muito que ele devia ter regressado se cumprisse o prometido

At tu lentus abes, nec te iurata reducunt

Numina, nec nostro motus amore redis

"Mas tu tardas, na tua ausência, e não te trazem de volta os deuses por quem juraste, e nem o meu amor te impele a regressar"

H.2.23-24.

Mariana vislumbrara um jovem oficial bem-parecido e valente; assim também Dido vira naquele estrangeiro troiano um homem de nobre raça (vide H. 7.90). Fílis, muito jovem ainda, tarde demais compreende que fora enganada, ela que era inocente e honesta antes de os caminhos de ambos se terem cruzado $(H$. 2.57-65). Tal como Dido, a nobreza da origem do rapaz fêla acreditar num enlace honrado. Também Mariana demonstra um enorme desconsolo por ter sido usada no seu amor puro e ingénuo por um militar experiente (vous n'avez regardé ma Passion que comme une victoire, et vostre coeur n'en a jamais esté profondément touché, Terceira Carta, p. 76). Fílis sente um enorme arrependimento por se ter deitado com Demofoonte e lhe ter ofertado a sua virgindade (vide $H .2 .49-51$ e $H .2 .115-116$ ), ao passo que Dido se arrepende de não ter resguardado a sua fidelidade conjugal a Siqueu (H. 7.93).

\section{Eros e Mania}

Para Ovídio, a mulher simbolizava a sedução e não se referia apenas às cortesãs, mas sim a todas as mulheres em geral, cujo principal ofício era seduzir e entregar-se ao seu sedutor. Todo o amor mais fero, o "amor-fogo", requeria a sujeição comum aos amantes ao longo dos tempos, da domina a quem o amante prestava a devida vassalagem. Este género de paixões comportava a perda da racionalidade ${ }^{12}$ e conhecia quase sempre um resultado

12 Cf. Ovídio, Amores, 2.9b.1-4: “...tão doce mal é a mulher”, "sou tomado por não sei que turbilhão de tristeza no meu coração" (tradução portuguesa de C. A. André, respectivamente pp. 227 e 229). 
funesto, fruto do desvario amoroso, como a união virgiliana de Dido e Eneias.

Ainda assim, em algumas cartas do corpus alcoforadista, denotam-se alguns assomos de lucidez

Cesse, cesse, Marianne infortunée, de te consumer vainement, et de chercher un Amant que tu ne verras jamais... qui ne pense pas un seul moment à tes douleurs, et qui te dispense de tous ces transports,

Primeira Carta, p. 65,

mas $\log$ a dor da paixão perdida tudo submete. Por muito que constantemente repita que deve esquecer o amante e enterrar as lembranças daquele funesto amor, Mariana continuamente se lhe dirige e aquela que diz ser a sua última carta parece nunca terminar. Falamos aqui, pois, da concepção do amor como uma doença, morbus, nosos, comum à literatura ao longo dos séculos: a sensação de um sentimento incurável

depuis que vous estes party, je n'ay pas eu un seul moment de santé et je n'ay aucun plaisir qu'en nommant vostre nom mille fois le jour,

Segunda Carta, p. 73

que culminaria com a morte, simbolizada, nas palavras de Mariana, pelo desmaio final ${ }^{13}$ da segunda carta:

Je suis au désespoir, vostre pauvre Marianne n'en peut plus, elle s'évanoüit en finissant cette lettre. Adieu, adieu, ayez pitié de moy,

Segunda Carta, p. 74.

13 O desmaio final era inúmeras vezes utilizado pelos autores: Fílis continuamente observava as ondas do mar, esperando ver chegar Demofoonte e desmaiava quando avistava navios no porto, caindo nos braços das criadas (H. 2.129130); Hero afirma a Leandro que também se deixará sucumbir, se ele tardar $(H .19 .8$ “deficiam parui temporis adde moram"); Briseida leva mais longe e mais tragicamente o seu amor, chegando a pedir a Aquiles que ele mesmo a mate. Se o amor que por ela sentia não mais o incendiava, seria preferível desaparecer do que viver num estado de profunda infelicidade (H. 3.141-142). 
São amantes furiosas, que vivem o seu amor até às entranhas, não desejando abandonar aquele sentimento esmagador, sob pena de perderem a razão que os sustém e faz viver (Primeira Carta, p. 66). Mesmo a doce e fiel Penélope vê o amor como "coisa cheia de angústia e medo" (Res est solliciti plena timoris amor, $H .1 .12$ ). Dido também sente quão penoso o amor pode ser, pois não é capaz de odiar Eneias, antes o ama cada vez mais (H. 7.29-30) e Fedra lança uma máxima que todo o amante deve seguir para não incorrer em ofensa aos deuses:

Quidquid Amor iussit, non est contemmere tutum

"tudo quanto o Amor ordena, desprezá-lo não é seguro"

\section{Mania}

Um estudo atento desta expressão de amor, levado a cabo por A. Aguiar, médico legista, trouxe à luz diversas hipóteses que explicam o exacerbamento da freira, convertendo-o não em amor profundo e louvável, mas num comportamento psíquico obsessivo, com laivos de morbidez e uma enorme instabilidade emocional, baseada também em desejos masoquistas. As expressões da freira caem, no parecer do especialista, no domínio claro da patologia ${ }^{14}$ : Je vous ay aimé comme une insensée (Quinta Carta, p. 99). O desequilíbrio emocional da jovem é fruto de diversos factores conjugados: a instabilidade política, a guerra no país, o facto de ter sido encerrada no convento muito nova (Quinta Carta, p. 101). Sofria ainda de desmaios, palpitações e crises nervosas. Os hábitos das flagelações, o jejum e as penitências diversas muito contribuíram para aumentar o terror do abandono. Além disso, em todo o seu sofrimento, oscila sempre "numa espécie de zigue-zague emocional"15 entre uma paixão que não é capaz de destruir e o desejo de dela se libertar (Primeira Carta, p. 66). Mariana seria masoquista a um nível psicológico, retirando prazer na humilhação, na tortura e na traição (Terceira Carta, p. 77). Após a partida do oficial, vivia angustiada com a ausência do amante e a sua clara indiferença (Primeira Carta, p. 66) mas apreciava o seu próprio sentimento doloroso e os sacrifícios que lhe destinava causavam-lhe prazer.

14 A. Aguiar, Soror Mariana: estudo sobre a religiosa portuguesa, p. 224.

15 C. A. André, "Tanto de meu estado me acho incerto", p. 45. 
Adieu, aymez-moy toujours; et faites-moy souffrir encore plus de maux. Primeira Carta, p. 67.

As amantes despeitadas consolam-se nas recordações de amor vividas: Ariadne procura no leito sinais da presença do amante, depois de ele a ter deixado à traição, enquanto ela dormia (H. 10.51-54). Safo passeia-se pelas grutas e bosques onde tantas vezes ela e o amante se juntavam para se amar, H. 15.141-145.

Mariana lembra como nasceu aquele amor funesto no seu peito e como cresceu e ele a foi ludibriando (vide Quarta Carta, p. 85), encantando o seu espírito até conseguir tê-la nos braços rendida (vide Quarta Carta, pp. 88-92). A jovem freira sabia que ele não lhe era fiel, embora tivesse alguma esperança (Quinta Carta, p. 98 ${ }^{16}$ ) e tais pensamentos prostravam-na profundamente. Em confidência, numa carta, Chamilly chega a dizer-lhe que amou outra mulher na sua terra. A jovem freira submeteu-se ao ex-amante e chega a afirmar que preferia tê-lo seguido para França e servi-lo, a ele e às mulheres que amasse, desde que, com isso, pudesse viver perto dele: $S$ 'il m'estoit possible de sortir de ce mal-heureux Cloistre, je n'attendrois pas en Portugal l'effet de vos promesses: j'irois sans garder aucune mesure vous chercher, vous suivre et vous aimer par tout le monde, Primeira Carta, p. 66.

Mariana pede, na sua resposta, que ele lhe envie um retrato dessa mulher: assim talvez conseguisse deixar de o amar.

Podemos observar o mesmo tipo de atitude nas Heroides: Dido deseja estar junto de Eneias, mesmo que ele não queira casar-se, pelo menos poderia tornar-se sua amante, é tudo quanto pede, ainda que fosse para a rainha uma desonra (H. 7.167-168); Briseida coloca a hipótese de ir viver com Aquiles e

16 Hipsípile também tem esperança de que os rumores sobre a amante bárbara de Jasão sejam falsos: "Obsequium, maneo si tua, grande tuli. / Barbara narratur uenisse uenefica tecum, / In mihi promissi parte recepta tori. / Credula res amor est. Utinam temeraria dicar / Criminibus falsis insimulasse uirum!", "Se continuo a ser tua, foi um grande favor que obtive. / Uma bruxa bárbara, conta-se, vem contigo / e é recebida na metade do leito que me estava prometido. / Coisa ingénua é o amor. Oxalá se diga que, sem pensar, / lancei falsas acusações contra o meu homem!", H. 6.18-22; Hero espera que sejam os ventos a retardar Leandro e não os braços de uma amante (H. 19.101-118). 
com a nova mulher a quem se uniu, desde que não a maltratem, pelo menos estaria junto dele (H.3.75-80). É o cúmulo da humilhação amorosa, a certeza de saber-se ultrapassada e esquecida. Mariana sente um sofrimento atroz ao tentar banir o amante do seu coração - j'aime mieux souffrir encore davantage, que vous oublier, Segunda Carta, p. 72 - maior e mais profundo do que o terror que experimentara quando se sentira abandonada e desprezada. Era-lhe mais querido o sentimento que vivia do que o homem como ser amado (Terceira Carta, p. 78) ${ }^{17}$.

Em certos momentos, a freira de Beja pensa mesmo em acabar com a vida (Je suis déchirée par mille mouvemens contraires...je me tuerois, ou je morrois de douleur sans me tuer, Terceira Carta, p. 76-77). Todas as mulheres pensam em matar-se perante a afronta de que são vítimas e revelam esse desejo aos ex-amantes: Fílis deseja atirar-se dos penhascos, beber veneno ou enforcar-se, $H$. 2.133-142; Dido afirma estar decidida a morrer, H. 7.181. Também Ariadne e Safo têm por objectivo primordial pôr fim à vida (respectivamente, $H .10 .81-82 ; H .15 .191-192$ ).

No entanto, as ameaças de morte e os votos de ruptura amorosa não nos parecem muito firmes nem seguros, pois a última carta parece não terminar, não há um adeus, uma despedida formal, reduzindo-se ao silêncio e à treva: Mariana deseja esquecer e terminar tudo, mas tal lampejo de lucidez não durará muito. A freira parece preferir o sofrimento profundo das lembranças que a perseguem do que a salvação que a ruptura lhe proporcionaria (Adieu, je voudrois bien ne vous avoir jamais veu, Terceira Carta, p. 78).

17 Este sentimento encontramo-lo em Medeia. É grande o despeito da bárbara por ter sido trocada por uma princesa rica. Medeia recrimina-se, perguntando-se por que se entregara àquele jovem guerreiro $(H .12 .7-18)$ e sente nessa recriminação um certo prazer (Est aliqua ingrato meritum exprobrare uoluptas, "Há um certo prazer na reprovação de serviços prestados a um ingrato", $H$. 12.21). 


\section{Conclusões}

"Estavas, linda Inês, posta em sossego" L. Camões, Os Lusíadas, III, 120-121

Também Mariana estava sossegada, encerrada nas paredes grossas do Convento, com pouca ligação ao exterior, a não ser pela janela de onde se avistava a rua movimentada e uma das portas da muralha de Beja. Exposta à brisa do Alentejo ensolarado, nessa varanda vislumbrou, ainda que ao longe, o pico da sua alegria como mulher, mas também a desgraça da sua vida: do regimento militar francês que aí treinava, uns olhares a surpreenderam e a sua visão deixou-se toldar, aos poucos, pela figura atraente de um cavaleiro da infantaria.

A vida da freira enclausurada não será mais a mesma de antes: a passagem do amante pelo seu quarto conferiu um novo sabor à sua clausura e o amor transtornou-a ao ponto de não mais suportar as paredes do Convento (vide Quarta Carta, p. 87).

Apesar de tudo, resta um sentimento minimamente positivo: é preferível sofrer um enorme desgosto do que nunca ter vivido o amor e nunca se ter sentido mulher (vide Terceira Carta, p. 79).

Com este ensaio, procurámos reflectir sobre o amor exacerbado, aquele que leva à loucura, ao ciúme e à humilhação total do amante. Cartas de amor como as que temos vindo a estudar são como um grito de dor e de arrebatamento, que procuram, através do suporte de papel, deixar uma marca no mundo, no destinatário ou, pelo menos, em quem as escreve, que encontra assim um meio de expressão mais digno e, ao mesmo tempo, catártico: j'écris plus pour moi que pour vous: je ne cherche qu'à me soulager, Quarta Carta, p. 92.

Tais expressões de amor denotavam, no fundo, um intenso desejo de não deixar morrer, pelo menos, a lembrança de carinhos e ardores partilhados, de juras mais íntimas e de sonhos que se esperava realizar (vide Segunda Carta, p. 71).

Quem nos garante, no fundo, que tenha sido realmente uma freira, até mesmo uma mulher e não um homem ${ }^{18}$ a escrever as cartas assinadas por

18 J. J. Rousseau afirmava que as cartas tinham sido escritas por um homem, alegando que uma mulher não seria capaz de sentir, nem de transmitir tais sentimentos 
Mariana? Tal como Ovídio, que se espraia nas suas cartas sob a máscara feminina de heroínas famosas da história e da mitologia, também as cartas de Mariana poderão esconder uma falsa identidade e não será através da sua obra necessariamente que se descobrirão novos dados. Um poeta, muitas vezes, constrói para si uma capa, uma outra identidade, através da qual deixa escapar os seus próprios pensamentos ou os de uma personagem completamente inventada e em nada semelhante a ele. Podemos sempre deixar-nos embalar pelos que acreditam acerrimamente nesta história de amor infeliz, um "amor grande demais para um só ser"19 e sorrir, pensando que, um dia, na pacata Beja do século XVII, existiu uma freira a quem um oficial francês encantou.

\section{Bibliografia}

\section{Edições, traduções e comentários}

Mariana Alcoforado, Cartas Portuguesas, tradução de Eugénio de Andrade, Lisboa, Assírio\&Alvim, 1998.

Ovide, Hérö̈des, traduit par M.Prévost, Paris, Les Belles Lettres, 1928.

Ovídio, Heroides, trad. de C. A. André, no prelo.

\section{Estudos}

A. Aguiar, Soror Mariana: estudo sobre a religiosa portuguesa, Lisboa, Portugália, 1924.

C. A. André, Caminhos do amor em Roma, sexo, amor e paixão na poesia latina do séc. I a.C., Lisboa, Livros Cotovia, 2006.

“' 'Tanto de meu estado me acho incerto': contradições do amor, de Catulo a Ovídio", Ágora 7, 2005, 37-63.

L. Cordeiro, Soror Mariana, a freira portuguesa, Lisboa, Livraria Ferin\&C. ${ }^{\text {, }}$ 1891.

A. B. Fonseca, Mariana Alcoforado, a freira de Beja e as "Lettres Portugaises", Lisboa, Imprensa Portugal-Brasil, 1966.

H. Jacobson, Ovid's Heroides, New Jersey, Princeton University Press, 1974.

amorosos e profundos, J. J. Rousseau, Oeuvres complètes, nouv. ed. Paris, Didier 1837.

19 Palavras de Jorge Sampaio no catálogo da exposição Do outro lado da grade. Soror Mariana e as Cartas Portuguesas, durante as comemorações do Dia de Portugal, no dia 10 de Junho do ano de 2002, decorridas em Beja. 
A. G. Rodrigues, "Sobre a autoria das Lettres Portugaises", separata da Biblos VIII, 1932.

Mariana Alcoforado, História e crítica de uma fraude literária, Coimbra, Coimbra Editora, 1935.

L. P. Wilkinson, Ovid surveyed, Cambridge, Cambridge University Press, 1962.

ANA SEIÇA CARVALHO 